\title{
Prospective associations between alcohol use, binge drinking and sexual activity in older adults: The English Longitudinal Study of Ageing
}

Igor Grabovac ${ }^{a *}$, Ai Koyanagib ${ }^{\mathrm{b}}$ Lin Yang ${ }^{\mathrm{c}}$, Guillermo F. López-Sánchez ${ }^{\mathrm{d}}$, Daragh McDermotte ${ }^{\mathrm{e}}$, Pinar Soysal ${ }^{\mathrm{f}}$, Ahmet Turan Isik $^{\mathrm{f}}$, Nicola Veronese ${ }^{\mathrm{g}}$, Lee Smith ${ }^{\mathrm{h} *}$

${ }^{a}$ Department of Social and Preventive Medicine, Centre for Public Health, Medical University Vienna, Austria;

${ }^{b}$ Instituto de Salud Carlos III, Centro de Investigación Biomédica en Red de Salud Mental, CIBERSAM, Madrid, Spain;

${ }^{c}$ Department of Epidemiology, Center for Public Health, Medical University of Vienna, Vienna, Austria;

${ }^{d}$ Faculty of Sport Sciences, University of Murcia, Spain;

e School of Psychology and Sport Science, Anglia Ruskin University, Cambridge, UK;

${ }^{f}$ Department of Geriatric Medicine, Faculty of Medicine, Bezmialem Vakif University, Istanbul, Turkey;

${ }^{g}$ National Research Council, Neuroscience Institute, Aging Branch, Padova, Italy;

${ }^{h}$ The Cambridge Centre for Sport and Exercise Sciences, Anglia Ruskin University, Cambridge, $U K$;

* Corresponding authors: Dr Igor Grabovac, Department of Social and Preventive Medicine, Centre for Public Health, Medical University Vienna, Austria igor.grabovac@meduniwien.ac.at and Dr Lee Smith, The Cambridge Centre for Sport and Exercise Sciences, Anglia Ruskin University, Cambridge lee.smith@anglia.ac.uk. Word count: 3377 . 


\begin{abstract}
The present study aimed to investigate associations between alcohol consumption, including binge drinking, and sexual activity. Data were from 1,622 men and 2,195 women aged $\geq 50$ years participating in the English Longitudinal Study of Ageing. Multivariable logistic regression was used to prospectively assess sex-specific associations between baseline frequency of alcohol use in the last year or binge drinking in the last week (self-reported in 2004/05) and sexual activity at 8-year followup (2012/13). Covariates included partner status, age, ethnicity, wealth, limiting long-standing illness, smoking status, physical activity, and depressive symptoms. After adjustment, regular alcohol consumption in the last year at baseline was associated with $111 \%$ higher odds (95\% CI 1.36-3.27) of any past-year sexual activity at follow-up in men and 76\% higher odds (95\% CI 1.26-2.46) in women, while frequent alcohol consumption was associated with $175 \%$ higher odds (95\% CI 1.75-4.32) of sexual activity in men and $100 \%$ higher odds (95\% CI 1.38-2.89) in women, relative to drinking alcohol never or rarely. Binge drinking was also positively associated with sexual activity at followup after adjustment for covariates, with odds of being sexually active at follow-up 52\% higher (95\% CI 1.07-2.15) among men who reported binge drinking at baseline and 57\% higher (95\% CI 1.112.23) among female binge drinkers. These results suggest that regular, frequent or binge drinking may protect against a decline in sexual activity as people grow old. While this does not outweigh the health risks associated with excessive alcohol consumption, health practitioners should consider the association between alcohol use and sexual activity when screening older adults for alcohol use and when encouraging older adults to reduce their alcohol consumption.
\end{abstract}

Key words: Alcohol, binge drinking, sexuality, sexual activity 


\section{Introduction}

Engaging in sexual activity has been shown to have benefits for older adults' mental and physical health and wellbeing. Studies have shown that a higher frequency of sexual activity is associated with a reduction in cardiovascular events in later life, reduced risk of fatal coronary events, prostate and breast cancer, and better reported quality of life (Bosland, 1988; Ebrahim et al., 2002; Flynn, \& Gow, 2015; Lê, Bachelot, \& Hill, 1989; Liu, Waite, Shen, \& Wang, 2016). However, despite the health benefits of engaging in sexual activity in later life, when individuals are at the greatest risk of developing chronic diseases, there tends to be a decline in sexual activity with age. In a population-based study of older English adults, sexual activity was found to decrease substantially from $50-59$ years to $\geq 80$ years in both men (from $94.1 \%$ to $31.1 \%$ ) and women (from $53.7 \%$ to $14.2 \%$ ) (Lee, Nazroo, O'Connor, Blake, \& Pendleton, 2015). A similar trend and magnitude of decline were also observed in a US population-based study (Lindau et al., 2007). Preventing such a decline in older adults may aid in the preservation of health and wellbeing in later life.

There is evidence to suggest that high alcohol consumption and binge alcohol use is associated with risky sexual outcomes, such as a greater number of sexual partners (Bazargan-Hejazi, Gaines, Bazargan, Seddighzadeh, \& Ahmadi, 2012; Carey, Senn, Walsh, Scott-Sheldon, \& Carey, 2016). However, how alcohol affects other sexual outcomes, such as engaging in sexual activity per se, is not known, particularly in older adults. The literature surrounding alcohol consumption and health is vast and complex. For example, a metaanalysis between alcohol consumption and health risks found a J-shaped relationship between alcohol intake and coronary heart disease risk, with a minimum relative risk of 0.80 at 20 $\mathrm{g}$ /day, a significant protective effect up to $72 \mathrm{~g} /$ day, and a significant increased risk at 89 g/day (Corrao, Bagnardi, Zambon, \& La Vecchia, 2004). The same meta-analysis also 
reported strong trends between alcohol consumption and increased risk for cancers of the oral cavity, oesophagus and larynx, hypertension, liver cirrhosis, and chronic pancreatitis (Corrao, Bagnardi, Zambon, \& La Vecchia, 2004). The literature on binge drinking and health is of great concern to health practitioners. The prevalence of binge drinking in western countries is high and rising, across all ages (Blazer, \& Wu, 2009; CDC, 2012; Miller, Naimi, Brewer, \& Jones, 2007; Naimi et al., 2003). Frequent binge drinking is associated with significantly worse health-related quality of life and mental distress, including stress, depression, and emotional problems (Okoro et al., 2004). Binge drinking has also been shown to be associated with certain cancers, such as those of the pancreas (Gupta, Wang, Holly, \& Bracci, 2010).

To our knowledge, no previous studies have examined relationships between alcohol use, including binge drinking, and sexual outcomes. If higher alcohol consumption is associated with poorer sexual outcomes then this is another way in which it may contribute to poor mental and physical health in later life. However, if alcohol use is positively associated with sexual activity, it may buffer against some of the adverse consequences of sexual inactivity. The present study aimed to explore prospective associations between alcohol consumption, including binge drinking, and sexual activity in a large, population-based sample of older adults over an eight-year follow-up.

\section{Method}

\section{Study population}

Data were from the English Longitudinal Study of Ageing (ELSA), a populationrepresentative longitudinal panel study of men and women aged 50 and older living in England (Steptoe, Breeze, Banks, \& Nazroo, 2013). Participants take part in biennial 
assessments, in which they complete a computer assisted personal interview and selfcompletion questionnaires. Baseline data for the present analyses are from Wave 2 of ELSA (2004/05; the first wave in which alcohol consumption was assessed in units) and follow-up data are from Wave $6(2012 / 13$; the only wave to date that has included assessment of sexual activity). We restricted our sample to those with data on sexual activity and at least one of the two alcohol outcome variables $(n=3,817)$. All participants gave full informed consent to participate in the study; the study complies with the declaration of Helsinki; and ethical approval was obtained from the London Multi-Centre Research Ethics Committee.

\section{Measures}

Measurement of exposures: alcohol consumption

Frequency of alcohol intake over the past 12 months was reported on an 8-point scale from "not at all in the last 12 months" to "almost every day" and categorised as never/rarely (never - once or twice a year), regularly (once every couple of months - twice a week), or frequently (3 days a week - almost every day) (Lee et al., 2015). Participants also completed a detailed record of the type (normal strength beer, lager, stout, cider or shandy/strong beer, lager, stout, cider or shandy/spirits or liquers/sherry or martini/wine/alcopops/other) and quantity (number of glasses/pints/large cans or bottles/small cans or bottles) of alcohol drinks consumed on the day in the last week on which they drank the most. The number of units of alcohol consumed was calculated and used to define binge drinking as $\geq 4$ units for women and $\geq 5$ units for men (CDC, 2018).

\section{Measurement of outcome: sexual activity}

Our primary outcome was past-year sexual activity, which was assessed with the question "Have you had any sexual activity (sexual intercourse, masturbation, petting or fondling) in 
the past year?" (yes/no). Secondary outcomes were past-month sexual intercourse, masturbation, and petting or fondling, each of which was dichotomised to frequent ( $\geq 2$ times) vs. infrequent ( $<2$ times), as has been done in previous investigations (Jackson et al., 2016; Lee et al., 2015). These items were administered as part of a self-completion questionnaire and returned in a sealed envelope. Participants were advised that all responses would be kept anonymous.

\section{Measurement of potential confounders}

All potential confounders were chosen prior to analyses being carried out owing to previous literature showing that they are independently associated with alcohol consumption (Boden \& Fergusson, 2011; Hajek, Bock, Weyerer, \& König, 2017; Leasure, Neighbors, Henderson, \& Young, 2015) and the outcome variables (Jackson et al., 2019; Smith, Grabovac, et al., 2019; Smith, Yang, et al., 2019).

Demographic information included age, sex, ethnicity (white vs. non-white), and partner status (married/cohabiting, separated/divorced, widowed, or single/never married). We used household non-pension wealth quintile (calculated across all ELSA Wave 6 participants) as an indicator of socio-economic status, as this measure has been shown to be particularly sensitive in this age group (Banks, Karlsen, \& Oldfield, 2003).

Health-related variables included self-reported limiting long-standing illness and smoking status (smoker vs. non-smoker). Physical activity was assessed with three items that asked participants how often they took part in vigorous, moderate, and low-intensity activities (more than once a week, once a week, 1-3 times a month, hardly ever/never) (Demakakos, Hamer, Stamatakis, \& Steptoe, 2010), and further categorised into three groups, as previously described: inactive (no moderate/vigorous activity on a weekly basis); moderate activity at 
least once a week; and vigorous activity at least once a week (Hamer, Molloy, de Oliveira, \& Demakakos, 2009). Depressive symptoms were assessed using the 8-item Centre of Epidemiological Studies Depression (CES-D) scale, a scale highly validated for use in older adults (Steffick, 2000) (Cronbach’s alpha $=0.78,95 \%$ CI 0.77-0.79).

Sexual orientation was assessed with the question: "Which statement best describes your sexual desires over your lifetime? Please include being interested in sex, fantasising about sex or wanting to have sex". Response options were 1) entirely for women, 2) mostly for women, but some desires for men, 3) equally for women and men, 4) mostly for men, but some desires for women, 5) entirely for men, and 6) no sexual desires in lifetime. We categorised participants with desires entirely for the opposite sex as straight, entirely for the same sex as gay and those endorsing response options 2,3 or 4 as bisexual. We coded the sexual orientation of those reporting no sexual desires as missing.

\section{Statistical analysis}

Analyses were performed using IBM SPSS Statistics 25. Data were weighted to correct for sampling probabilities and for differential non-response and to calibrate back to the 2011 National Census population distributions for age and sex. The weights accounted for the differential probability of being included in Wave 6 of ELSA and for non-response to the questionnaire assessing sexual activity. Details can be found at http://doc.ukdataservice.ac.uk/doc/5050/mrdoc/pdf/5050_elsa_w6_technical_report_v1.pdf

Analyses were performed separately for men and women. We used chi-square tests to analyse bivariate associations between (i) the frequency of alcohol consumption and (ii) binge drinking at baseline, and past-year sexual activity at eight-year follow-up. For analyses 
of frequency of alcohol consumption (a 3-level variable), we performed post-hoc paired comparisons where the omnibus test result was statistically significant. Multivariable logistic regression was then used to test independent associations between baseline frequency of alcohol consumption and binge drinking and past-year sexual activity at follow-up, adjusting for age, partner status, ethnicity, wealth, limiting long-standing illness, smoking status, physical activity and depressive symptoms at baseline. To test for differences in associations by sexual orientation, we reran models including sexual orientation as an independent variable and tested interactions with alcohol consumption/binge drinking. To test the extent to which associations differed across the component parts of the broad measure of past-year sexual activity, we repeated these analyses using frequent ( $\geq 2$ times) sexual intercourse, masturbation, and petting/fondling over the past month (because this information was not available for the past year) as outcomes. In addition, we expected that sexual activity at follow-up might be more strongly influenced by current versus past status on time-varying confounders (e.g. partner status, limiting long-standing illness, depressive symptoms); thus, we performed a sensitivity analysis in which data on all covariates were drawn from the follow-up rather than baseline wave for the logistic regression models.

\section{Results}

There were 1,622 men (mean [SD] age at baseline $=63.6$ [8.2] years) and 2,195 women (64.8 [9.0] years) in the sample. Sample characteristics are summarised in Table 1. At baseline, $11.8 \%$ of men reported drinking never/rarely (up to twice a year) in the last year, $42.9 \%$ reported drinking regularly (between once every couple of months and twice a week) and $45.3 \%$ reported drinking frequently (at least 3 days a week). Drinking frequency was slightly lower among women, with $24.5 \%$ reporting drinking never/rarely, $47.2 \%$ drinking regularly and $28.3 \%$ drinking frequently. Around one in five men $(20.2 \%)$ and one in eight women 
$(12.7 \%)$ reported binge drinking (consuming $\geq 5$ units in one day for men and $\geq 4$ units for women) in the last week.

At eight-year follow-up, $65.9 \%$ of men and $40.4 \%$ of women reported having engaged in any sexual activity in the last year. The bivariate association between frequency of alcohol consumption over the last year at baseline and sexual activity at eight-year follow-up was statistically significant in both men and women $(p<0.001)$ (Table 2$)$. Among men, the prevalence of sexual activity was $45.3 \%$ among those who drank alcohol never or rarely, $65.4 \%$ among those who drank regularly, and $73.6 \%$ among those who drank frequently. Among women, the respective figures were $23.9 \%, 44.6 \%$ and $51.9 \%$. There was also a significant bivariate association between binge drinking in the last week at baseline and sexual activity at follow-up, with a higher prevalence of sexual activity among male $(77.3 \%$ vs. $63.0 \%, p<0.001)$ and female $(62.3 \%$ vs. $37.2 \%, p<0.001)$ binge drinkers (Table 2$)$.

While alcohol consumption and binge drinking did not differ significantly between men who were and were not partnered ( $p=0.089$ and $p=0.431$, respectively), married/cohabiting women were significantly more likely than those who were single to drink frequently $(31.9 \%$ vs. $22.2 \%, p<0.001)$ and to binge drink $(15.0 \%$ vs. $8.7 \%, p<0.001)$ which could have accounted for differences in sexual activity. After adjustment for partner status and other relevant covariates (age, ethnicity, wealth, limiting long-standing illness, smoking status, physical activity and depressive symptoms) at baseline, regular alcohol consumption in the last year at baseline was associated with $111 \%$ higher odds of sexual activity at followup in men $(\mathrm{OR}=2.11,95 \% \mathrm{CI} 1.36-3.27)$ and $76 \%$ higher odds in women $(\mathrm{OR}=1.76,95 \% \mathrm{CI}$ 1.26-2.46) and frequent alcohol consumption was associated with $175 \%$ higher odds of sexual activity in men $(\mathrm{OR}=2.75,95 \%$ CI $1.75-4.32)$ and $100 \%$ higher odds in women $(\mathrm{OR}=2.00,95 \% \mathrm{CI} 1.38-2.89)$, relative to drinking alcohol never or rarely (Table 3). Binge 
drinking was also positively associated with sexual activity after adjustment for covariates, with odds of being sexually active at follow-up 52\% higher among men who reported binge drinking at baseline $(\mathrm{OR}=1.52,95 \%$ CI $1.07-2.15)$ and 57\% higher among female binge drinkers $(\mathrm{OR}=1.57,95 \% \mathrm{CI} 1.11-2.23)$. There were no significant interactions between sexual orientation and frequency of alcohol consumption (men $p=0.319$, women $p=0.975$ ) or binge drinking ( $\operatorname{men} p=1.00$, women $p=0.852$ ).

Adjusting for covariates measured at follow-up rather than baseline did not notably alter the pattern of results, although effect sizes for men were slightly reduced (Supplementary Table 1).

Secondary analyses of frequent past-month sexual intercourse, masturbation, and petting/fondling produced a similar pattern of results. Unadjusted analyses showed significant associations of more frequent alcohol consumption and binge drinking with frequent sexual activities (Supplementary Table 2). The only exception was frequency of alcohol consumption and frequent masturbation in women, which did not reach statistical significance. Effect sizes were generally smaller in the adjusted models of past-month sexual activities than was observed in the primary analyses of past-year sexual activity, with women reporting frequent alcohol consumption more likely to engage in sexual intercourse and petting/fondling ( $\geq 2$ times per month). Also, for women, binge drinking was associated with masturbation. The only statistically significant finding for men was that frequent alcohol consumption was associated with greater past month sexual intercourse ( $\geq 2$ times per month) (Supplementary Table 3).

\section{Discussion}

In this large, representative sample of older English adults, the results have revealed novel prospective associations of regular alcohol consumption and binge drinking with sexual 
activity. The majority of men and women reported drinking alcohol regularly or frequently in the last year, and one in five men and one in eight women reported binge drinking in the last week. Importantly, those who reported regular/frequent alcohol consumption or binge drinking at baseline were substantially more likely to be sexually active at 8-year follow-up than those with lower levels of alcohol consumption. These associations hold true regardless of sexual orientation.

These findings are in line with previous research reporting higher levels of alcohol consumption and binge drinking among older adults (Blazer, \& Wu, 2009; Barnes et al., 2010), and add to evidence linking alcohol consumption with more risky sexual outcomes, such as a greater number of sexual partners (Bazargan-Hejazi et al., 2012; Carey et al., 2016). To our knowledge, no previous studies have examined the relationship between alcohol intake and sexual outcomes.

The present findings suggest that regular or frequent alcohol consumption and binge drinking may protect against a decline in any sexual activity as people age. Previous studies have shown that alcohol enhances sexual desire, enjoyment, and activity (Harvey, \& Beckman, 1986). One plausible mechanism may be that alcohol intake enhances sexual arousal, which leads to greater sexual activity (Cooper, 1992). Therefore, those who drink alcohol on a regular basis at high dosage may engage in sexual activity more often. Moreover, literature also suggests that the anticipated effects of alcohol provide a reason for sexual expression that may be unlikely under sober conditions (Cooper, 1992). The orbitofrontal cortex, which plays a role in the human response to visual sexual stimuli (Redouté et al., 2000) and feelings of intoxication (Mitchell et al., 2012), may also be implicated. However, further research is needed to understand the role it plays in the association between drinking behaviour and sexual activity. Alternatively, it is possible that 
individuals who drink may be more sociable and also more likely to go out than their nondrinking counterparts; sociability may increase the odds of meeting a partner and, subsequently, having sexual interactions.

Sexual activity has been shown to be beneficial for physical and mental health (Lê et al., 1989; Liu et al., 2016) but declines in older age (Lee et al., 2015). Interestingly, the present results suggest that regular alcohol use and binge drinking might protect against this age-related decline. Given the detrimental effects of drinking alcohol at high levels (Okoro et al., 2004), we do not advocate that older adults drink to excess in order to maintain sexual activity. Rather, we suggest two important clinical implications. First, owing to the positive health effects of engaging in sexual activity, health practitioners should be encouraged to engage in conversations with older adults to prevent a decline in sexual activity as people age. Health practitioners often screen older adults on alcohol consumption; those who consume no or very little alcohol should be considered a group at risk of low and declining sexual activity. Second, older adults who are encouraged by health practitioners to reduce alcohol consumption should be given advice and/or counselling to support them in maintaining a healthy and active sex life.

Strengths of the present study include the longitudinal design and a large, representative sample of older English adults. However, findings from the present study must be interpreted in light of its limitations. Alcohol consumption and sexual activity were both self-reported, and assessment of alcohol intake required accurate recall of the amount consumed on the heaviest drinking day in the last week, introducing scope for bias. However, self-reports of alcohol consumption have been shown to have high reliability and it is generally accepted that these measures can be used with considerable confidence (Williams, Aitken, \& Malin, 1985). Moreover, items on alcohol and sexual activity were assessed via 
self-completion questionnaire rather than in the face-to-face interview; the questionnaires were returned in a sealed envelope; and it was made clear to participants that survey responses would remain anonymous.

In conclusion, the present study found that regular, frequent or binge drinking may protect against a decline in sexual activity as people grow old. Health practitioners should consider this when screening older adults for alcohol use and when encouraging older adults to reduce their alcohol consumption.

\section{Author Contributions statement}

IG and LS conceived the idea. LS carried out statistical analyses. IG and LS interpreted the findings. IG and LS drafted the manuscript. All authors provided extensive comments on the draft manuscript and approved the final version before submission.

\section{Conflicts of interest}

The authors declare that they have no conflicts of interest.

\section{Funding}

This research received no specific grant from any funding agency in the public, commercial, or not-for-profit sectors.

\section{Data availability statement}

All data are available at https://www.ukdataservice.ac.uk/about-us/contact 


\section{References}

Banks, J., Karlsen, S., \& Oldfield, Z. (2003). Socio-economic position. Retrieved from http://discovery.ucl.ac.uk/15366/1/15366.pdf

Barnes, A. J., Moore, A. A., Xu, H., Ang, A., Tallen, L., Mirkin, M., \& Ettner, S. L. (2010). Prevalence and correlates of at-risk drinking among older adults: The Project SHARE Study. Journal of General Internal Medicine, 25(8), 840-846.

Bazargan-Hejazi, S., Gaines, T., Bazargan, M., Seddighzadeh, B., \& Ahmadi, A. (2012). Alcohol misuse and multiple sexual partners. The Western Journal of Emergency Medicine, 13(2), 151-159.

Blazer, D. G., \& Wu, L. T. (2009). The Epidemiology of at-risk and binge drinking among middle-aged and elderly community adults: National Survey on Drug Use and Health. American Journal of Psychiatry, 166(10), 1162-1169.

Boden, J. M., \& Fergusson, D. M. (2011). Alcohol and depression. Addiction, 106(5), 906914.

Bosland, M. C. (1988). The etiopathogenesis of prostatic cancer with special reference to environmental factors. Advances in Cancer Research, 51, 1-106.

Carey, K. B., Senn, T. E., Walsh, J. L., Scott-Sheldon, L. A. J., \& Carey, M. P. (2016). Alcohol use predicts number of sexual partners for female but not male STI clinic patients. AIDS and Behavior, 20(1), 52-59.

CDC (2018). Fact Sheets-Binge drinking - alcohol. Retrieved from https://www.cdc.gov/alcohol/fact-sheets/binge-drinking.htm

Centers for Disease Control and Prevention (CDC). (2012). Vital signs: binge drinking prevalence, frequency, and intensity among adults - United States, 2010. Morbidity and Mortality Weekly Report, 61(1), 14-19.

Cooper, M. L. (1992). Alcohol and increased behavioral risk for AIDS. Alcohol health and research world, 16(1), 64-72. 
Corrao, G., Bagnardi, V., Zambon, A., \& La Vecchia, C. (2004). A meta-analysis of alcohol consumption and the risk of 15 diseases. Preventive Medicine, 38(5), 613-619.

Demakakos, P., Hamer, M., Stamatakis, E., \& Steptoe, A. (2010). Low-intensity physical activity is associated with reduced risk of incident type 2 diabetes in older adults: evidence from the English Longitudinal Study of Ageing. Diabetologia, 53, 1877-1885.

Ebrahim, S., May, M., \& Shlomo, Y. B., McCarron, P., Frankel, S., Yarnell, J., \& Smith, G. D. (2002). Sexual intercourse and risk of ischaemic stroke and coronary heart disease: the Caerphilly study. Journal of Epidemiology and Community Health, 56(2), 99-102.

Flynn, T. J., \& Gow, A. J. (2015). Examining associations between sexual behaviours and quality of life in older adults. Age Ageing, 44(5), 823-828.

Gupta, S., Wang, F., Holly, E. A., \& Bracci, P. M. (2010). Risk of pancreatic cancer by alcohol dose, duration, and pattern of consumption, including binge drinking: a populationbased study. Cancer Causes Control, 21(7), 1047-1059.

Hajek, A., Bock, J.-O., Weyerer, S., \& König, H.-H. (2017). Correlates of alcohol consumption among Germans in the second half of life. Results of a population-based observational study. BMC Geriatrics, 17.

Hamer, M., Molloy, G. J., de Oliveira, C., \& Demakakos, P. (2009). Leisure time physical activity, risk of depressive symptoms, and inflammatory mediators: the English Longitudinal Study of Ageing. Psychoneuroendocrinology, 34(7), 1050-1055.

Harvey, S. M., \& Beckman, L. J. (1986). Alcohol consumption, female sexual behavior and contraceptive use. Journal of Studies on Alcohol and Drugs, 47(4), 327-332.

Jackson, S. E., Yang, L., Veronese, N., Koyanagi, A., Sánchez, G. F. L., Grabovac, I., ... Smith, L. (2019). Sociodemographic and behavioural correlates of lifetime number of sexual partners: findings from the English Longitudinal Study of Ageing. BMJ Sex Reprod Health, $45(2), 138-146$.

Jackson, S. E., Wardle, J., Steptoe, A., \& Fisher, A. (2016). Sexuality after a cancer diagnosis: a population-based study. Cancer, 122(24), 3883-3891. 
Leasure, J. L., Neighbors, C., Henderson, C. E., \& Young, C. M. (2015). Exercise and alcohol consumption: what we know, what we need to know, and why it is important. Frontiers in Psychiatry, 6.

Lê, M. G., Bachelot, A., \& Hill, C. (1989). Characteristics of reproductive life and risk of breast cancer in a case-control study of young nulliparous women. Journal of Clinical Epidemiology, 42(12), 1227-1233.

Lee, D.M., Nazroo, J., O’Connor, D.B., Blake, M., \& Pendleton, N. (2015). Sexual health and well-being among older men and women in England: findings from the English Longitudinal Study of Ageing. Archives of Sexual Behavior, 45(1), 133-144.

Lindau, S. T., Schumm, L. P., Laumann, E. O., Levinson, W., O'Muircheartaigh, C. A., \& Waite, L. J. (2007). A study of sexuality and health among older adults in the United States. The New England Journal of Medicine, 357(8), 762-774.

Liu, H., Waite, L., Shen, S., \& Wang, D. (2016). Is sex good for your health? A national study on partnered sexuality and cardiovascular risk among older men and women. Journal of Health and Social Behavior, 57(3), 276-296.

Miller, J. W., Naimi, T. S., Brewer, R. D., \& Jones, S. E. (2007). Binge drinking and associated health risk behaviors among high school students. Pediatrics, 119(1), 76-85.

Mitchell, J. M., O’neil, J. P., Janabi, M., Marks, S. M., Jagust, W. J., \& Fields, H. L. (2012). Alcohol consumption induces endogenous opioid release in the human orbitofrontal cortex and nucleus accumbens. Science Translational Medicine, 4(116), 116ra6-116ra6.

Naimi, T. S., Brewer, R. D., Mokdad, A., Denny, C., Serdula, M. K., \& Marks, J. S. (2003). Binge drinking among US adults. JAMA, 289(1), 70-75.

Okoro, C. A., Brewer, R. D., Naimi, T. S., Moriarty, D. G., Giles, W. H., \& Mokdad, A. H. (2004). Binge drinking and health-related quality of life: do popular perceptions match reality? American Journal of Preventive Medicine, 26(3), 230-233.

Redouté, J., Stoléru, S., Grégoire, M. C., Costes, N., Cinotti, L., Lavenne, F., ... \& Pujol, J. F. (2000). Brain processing of visual sexual stimuli in human males. Human Brain Mapping, 11(3), 162-177. 
Smith, L., Grabovac, I., Yang, L., Veronese, N., Koyanagi, A., \& Jackson, S. E. (2019).

Participation in physical activity is associated with sexual activity in older English adults. International Journal of Environmental Research and Public Health, 16(3).

Smith, L., Yang, L., Veronese, N., Soysal, P., Stubbs, B., \& Jackson, S. E. (2019). Sexual activity is associated with greater enjoyment of life in older adults. Sexual Medicine, 7(1), $11-18$.

Steffick, D. E. (2000). Documentation of affective functioning measures in the Health and Retirement Study. HRS Documentation Report, DR-005.

Steffick, D. E. (2000). Documentation of affective functioning measures in the Health and Retirement Study. Ann Arbor, MI, USA: University of Michigan.

Steptoe, A., Breeze, E., Banks, J., \& Nazroo, J. (2013). Cohort profile: the English Longitudinal Study of Ageing. International Journal of Epidemiology, 42(6), 1640-1648.

Williams, G. D., Aitken, S. S., \& Malin, H. (1985). Reliability of self-reported alcohol consumption in a general population survey. Journal of Studies on Alcohol and Drugs, 46(3), $223-227$. 
Tables

Table 1 Sample characteristics at baseline

\begin{tabular}{|c|c|c|}
\hline & $\begin{array}{c}\text { Men } \\
(n=1622)\end{array}$ & $\begin{array}{c}\text { Women } \\
(n=2195)\end{array}$ \\
\hline Age (mean [SD] years) & $63.64(8.19)$ & $64.77(9.03)$ \\
\hline \multicolumn{3}{|l|}{ Partner status } \\
\hline Married/cohabiting & 79.4 & 63.0 \\
\hline Separated/divorced & 9.2 & 12.7 \\
\hline Widowed & 6.2 & 20.0 \\
\hline Single/never married & 5.3 & 4.2 \\
\hline \multicolumn{3}{|l|}{ Ethnicity } \\
\hline White & 95.9 & 97.5 \\
\hline Non-white & 4.1 & 2.5 \\
\hline \multicolumn{3}{|l|}{ Wealth quintile } \\
\hline 1 (poorest) & 12.9 & 18.0 \\
\hline 2 & 19.0 & 20.2 \\
\hline 3 & 20.7 & 19.5 \\
\hline 4 & 22.5 & 21.6 \\
\hline 5 (richest) & 25.0 & 20.7 \\
\hline \multicolumn{3}{|l|}{ Limiting long-standing illness } \\
\hline Yes & 28.4 & 33.6 \\
\hline No & 71.6 & 66.4 \\
\hline \multicolumn{3}{|l|}{ Smoking status } \\
\hline Smoker & 14.6 & 14.5 \\
\hline Non-smoker & 85.4 & 85.5 \\
\hline $\begin{array}{l}\text { Depressive symptoms }(0-8) \text { (mean } \\
\text { [SD]) }\end{array}$ & $1.15(1.70)$ & $1.71(2.04)$ \\
\hline \multicolumn{3}{|l|}{ Sexual orientation } \\
\hline Heterosexual & 93.6 & 88.0 \\
\hline Bisexual & 2.3 & 4.0 \\
\hline Lesbian/gay & 1.0 & 0.4 \\
\hline Missing & 3.0 & 7.6 \\
\hline \multicolumn{3}{|l|}{ Alcohol intake ${ }^{1}$} \\
\hline Never/rarely & 11.8 & 24.5 \\
\hline Regularly & 42.9 & 47.2 \\
\hline Frequently & 45.3 & 28.3 \\
\hline \multicolumn{3}{|l|}{ Binge drinking $^{2}$} \\
\hline Yes & 20.2 & 12.7 \\
\hline No & 79.8 & 87.3 \\
\hline
\end{tabular}

Values are percentages unless otherwise stated.

All figures are weighted for sampling probabilities and differential non-response.

$\mathrm{SD}=$ standard deviation .

${ }^{1}$ Never/rarely $=$ never - once or twice a year; regularly $=$ once every couple of months - twice a week; frequently $=3$ days a week - almost every day.

${ }^{2}$ Defined as drinking $\geq 4$ units for women and $\geq 5$ units for men on the heaviest drinking day in the past week. 
Table 2 Prevalence of past-year sexual activity (intercourse, masturbation, petting or fondling) at follow-up in relation to frequency of alcohol intake and binge drinking at baseline in men and women

\begin{tabular}{|c|c|c|c|c|c|c|}
\hline & \multicolumn{3}{|c|}{ Men } & \multicolumn{3}{|c|}{ Women } \\
\hline & $\begin{array}{l}\text { Sexually } \\
\text { active }\end{array}$ & $\begin{array}{c}\text { Not } \\
\text { sexually } \\
\text { active } \\
\end{array}$ & $p$ & $\begin{array}{c}\text { Sexually } \\
\text { active }\end{array}$ & $\begin{array}{c}\text { Not } \\
\text { sexually } \\
\text { active } \\
\end{array}$ & $p$ \\
\hline $\begin{array}{l}\text { Frequency of } \\
\text { alcohol } \\
\text { consumption }{ }^{1}\end{array}$ & & & & & & \\
\hline Never/rarely & $45.3^{\mathrm{a}, \mathrm{b}}$ & 54.7 & $<0.001$ & $23.9^{\mathrm{a}, \mathrm{b}}$ & 76.1 & $<0.001$ \\
\hline Regularly & $65.4^{\mathrm{a}, \mathrm{c}}$ & 34.6 & - & $44.6^{\mathrm{a}, \mathrm{c}}$ & 55.4 & - \\
\hline Frequently & $73.6^{\mathrm{b}, \mathrm{c}}$ & 26.4 & - & $51.9^{\mathrm{b}, \mathrm{c}}$ & 48.1 & - \\
\hline Binge drinking $^{2}$ & & & & & & \\
\hline Yes & 77.3 & 22.7 & $<0.001$ & 62.3 & 37.7 & $<0.001$ \\
\hline No & 63.0 & 37.0 & - & 37.2 & 62.8 & - \\
\hline
\end{tabular}

Values are percentages.

All figures are weighted for sampling probabilities and differential non-response.

${ }^{1}$ Never/rarely $=$ never - once or twice a year; regularly $=$ once every couple of months - twice a week; frequently $=3$ days a week - almost every day.

${ }^{2}$ Defined as drinking $\geq 4$ units for women and $\geq 5$ units for men on the heaviest drinking day in the past week.

a,b,c Pairwise comparisons following a significant omnibus chi-square test indicated groups differed significantly from one another. 
Table 3 Adjusted associations between frequency of alcohol intake and binge drinking at baseline and past-year sexual activity (intercourse, masturbation, petting or fondling) at eight-year follow-up in men and women

\begin{tabular}{lccccc}
\hline & \multicolumn{2}{c}{ Men } & & \multicolumn{2}{c}{ Women } \\
\cline { 2 - 3 } \cline { 5 - 6 } & OR [95\% CI] & $\boldsymbol{p}$ & & OR [95\% CI] & $\boldsymbol{p}$ \\
\hline $\begin{array}{l}\text { Frequency of alcohol } \\
\text { consumption }\end{array}$ & & & & \\
$\quad$ Never/rarely & 1.00 & - & & 1.00 & - \\
\hline Regularly & $2.11[1.36-3.27]$ & 0.001 & & $1.76[1.26-2.46]$ & 0.001 \\
\hline Frequently & $2.75[1.75-4.32]$ & $<0.001$ & & $2.00[1.38-2.89]$ & $<0.001$ \\
\hline $\begin{array}{l}\text { Binge drinking } \\
\text { No }\end{array}$ & 1.00 & - & & 1.00 & - \\
\hline Yes & $1.52[1.07-2.15]$ & 0.019 & & $1.57[1.11-2.23]$ & 0.010 \\
\hline
\end{tabular}

$\mathrm{OR}=$ odds ratio; $\mathrm{CI}=$ confidence interval.

All figures are adjusted for age, partner status, ethnicity, wealth, limiting long-standing illness, smoking status, physical activity and depressive symptoms at baseline, and weighted for sampling probabilities and differential non-response.

${ }^{1} \mathrm{Never} /$ rarely $=$ never - once or twice a year; regularly $=$ once every couple of months - twice a week; frequently $=3$ days a week - almost every day.

${ }^{2}$ Defined as drinking $\geq 4$ units for women and $\geq 5$ units for men on the heaviest drinking day in the past week. 
Supplementary Table 1 Adjusted associations between frequency of alcohol intake and binge drinking at baseline and sexual activity at eight-year follow-up in men and women: sensitivity analyses adjusting for covariates measured at follow-up

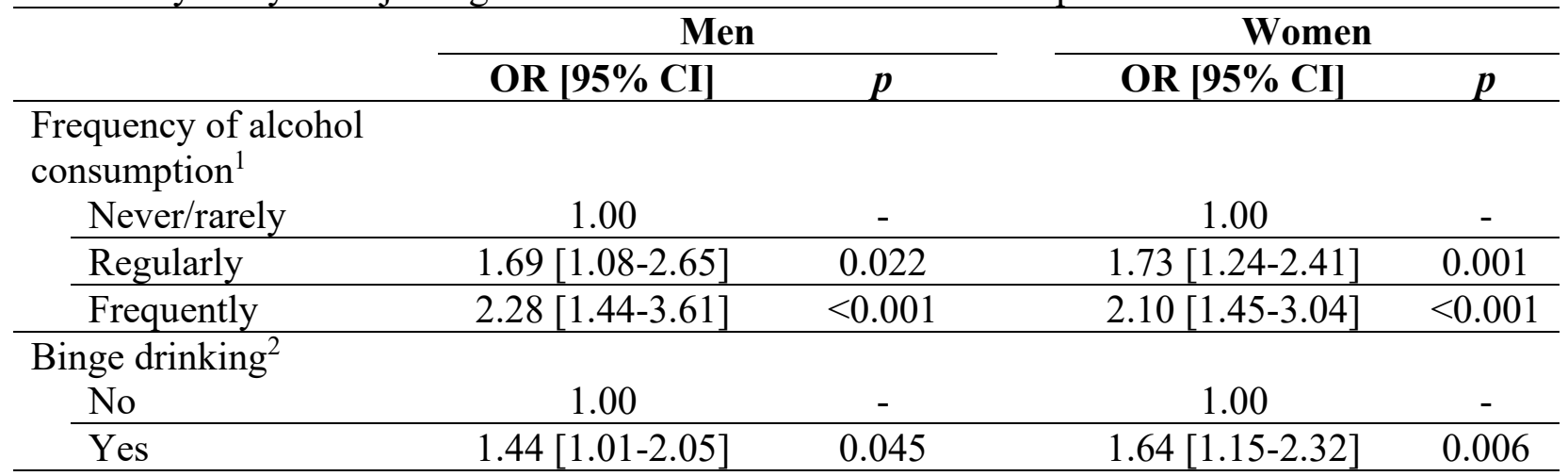

$\mathrm{OR}=$ odds ratio; $\mathrm{CI}=$ confidence interval.

All figures are adjusted for age, partner status, ethnicity, wealth, limiting long-standing illness, smoking status, physical activity and depressive symptoms at follow-up, and weighted for sampling probabilities and differential non-response.

${ }^{1} \mathrm{Never} /$ rarely $=$ never - once or twice a year; regularly $=$ once every couple of months - twice a week; frequently $=3$ days a week - almost every day.

${ }^{2}$ Defined as drinking $\geq 4$ units for women and $\geq 5$ units for men on the heaviest drinking day in the past week. 
Supplementary Table 2 Prevalence of frequent ( $\geq 2$ times) past-month sexual intercourse, masturbation, and petting or fondling at follow-up in relation to frequency of alcohol intake and binge drinking at baseline in men and women

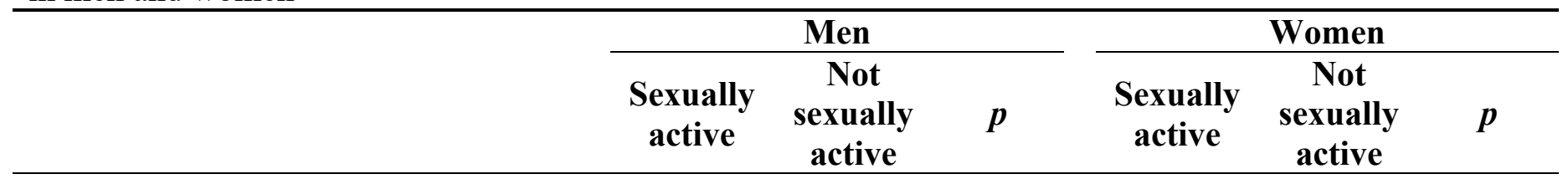

\section{Sexual intercourse}

Frequency of alcohol consumption ${ }^{1}$

\begin{tabular}{lcccccc} 
Never/rarely & $16.2^{\mathrm{a}}$ & 83.8 & $<0.001$ & $7.9^{\mathrm{a}, \mathrm{b}}$ & 92.1 & $<0.001$ \\
\hline Regularly & $21.6^{\mathrm{b}}$ & 78.4 & - & $17.9^{\mathrm{a}, \mathrm{c}}$ & 82.1 & - \\
\hline $\begin{array}{l}\text { Frequently } \\
\text { ge drinking }\end{array}$ & $30.5^{\mathrm{a}, \mathrm{b}}$ & 69.5 & - & $22.7^{\mathrm{b}, \mathrm{c}}$ & 77.3 & - \\
$\begin{array}{l}\text { Yes } \\
\text { No }\end{array}$ & 30.7 & 69.3 & 0.009 & 27.6 & 72.4 & $<0.001$ \\
\hline
\end{tabular}

\section{Masturbation}

Frequency of alcohol consumption ${ }^{1}$

\begin{tabular}{|c|c|c|c|c|c|c|}
\hline Never/rarely & $16.2^{\mathrm{a}, \mathrm{b}}$ & 83.8 & 0.004 & 3.2 & 96.8 & 0.059 \\
\hline Regularly & $22.0^{\mathrm{a}, \mathrm{c}}$ & 78.0 & - & 4.4 & 95.6 & - \\
\hline Frequently & $28.0^{\mathrm{b}, \mathrm{c}}$ & 72.0 & - & 6.6 & 93.4 & - \\
\hline \multicolumn{7}{|l|}{ Binge drinking $^{2}$} \\
\hline Yes & 31.0 & 69.0 & 0.002 & 9.1 & 90.9 & 0.001 \\
\hline No & 22.0 & 78.0 & - & 3.9 & 96.1 & - \\
\hline
\end{tabular}

\section{Petting/fondling}

Frequency of alcohol consumption ${ }^{1}$

\begin{tabular}{|c|c|c|c|c|c|c|}
\hline Never/rarely & $26.4^{\mathrm{a}}$ & 73.6 & $<0.001$ & $11.9^{\mathrm{a}}$ & 88.1 & $<0.001$ \\
\hline Regularly & $37.4^{\mathrm{b}}$ & 62.6 & - & 27.6 & 72.4 & - \\
\hline Frequently & $45.1^{\mathrm{a}, \mathrm{b}}$ & 54.9 & - & $35.0^{\mathrm{a}}$ & 65.0 & - \\
\hline \multicolumn{7}{|l|}{ Binge drinking ${ }^{2}$} \\
\hline Yes & 44.6 & 55.4 & 0.021 & 39.3 & 60.7 & $<0.001$ \\
\hline No & 37.0 & 63.0 & - & 22.6 & 77.4 & - \\
\hline
\end{tabular}

Values are percentages.

All figures are weighted for sampling probabilities and differential non-response.

${ }^{1}$ Never/rarely $=$ never - once or twice a year; regularly = once every couple of months - twice a week; frequently $=3$ days a week - almost every day.

${ }^{2}$ Defined as drinking $\geq 4$ units for women and $\geq 5$ units for men on the heaviest drinking day in the past week.

a,b,c Matching letters indicate that groups differed significantly from one another in pairwise comparisons following a significant omnibus chi-square test (i.e. for each association between frequency of alcohol consumption and sexual activity, groups marked ${ }^{a}$ differ significantly from other groups marked ${ }^{\mathrm{a}}$, etc.). 
Supplementary Table 3 Adjusted associations between frequency of frequent $(\geq 2$ times) past-month sexual intercourse, masturbation, and petting or fondling at eight-year follow-up in men and women

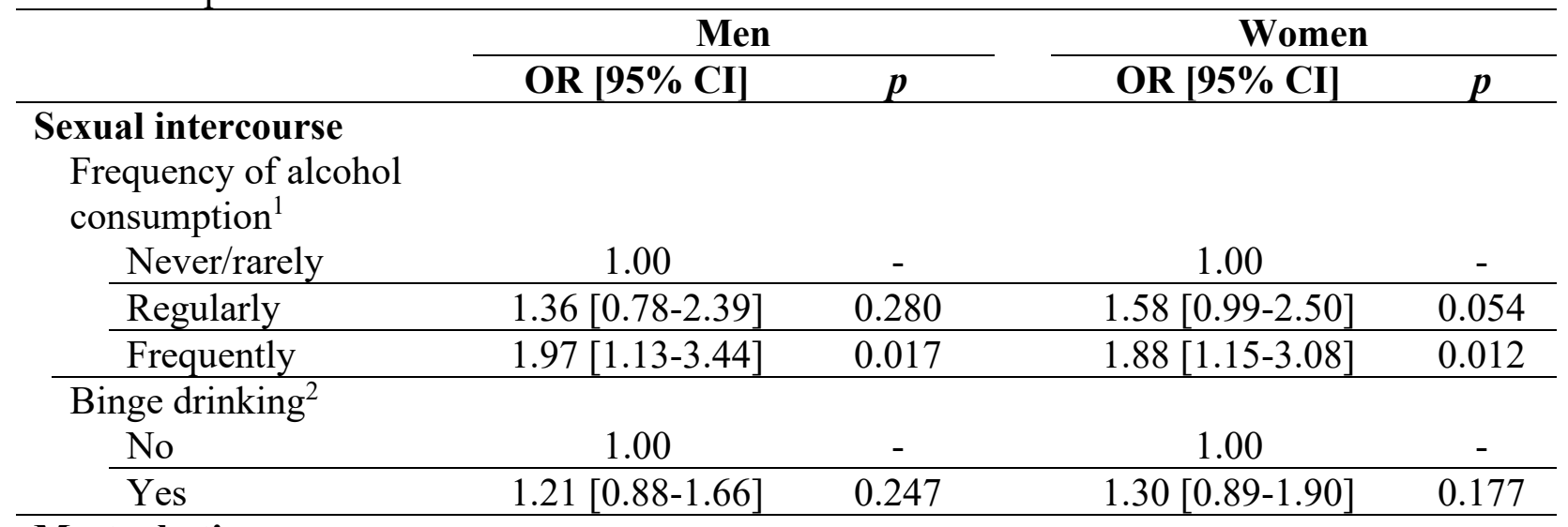

\section{Masturbation}

Frequency of alcohol consumption $^{1}$

Never/rarely

Regularly

1.00

$1.23[0.72-2.10] \quad 0.454$

1.00

Frequently

$1.51[0.88-2.57] \quad 0.132$

$1.01[0.49-2.08] \quad 0.978$

Binge drinking ${ }^{2}$

\begin{tabular}{lcccc} 
No & 1.00 & - & 1.00 & - \\
\hline Yes & $1.26[0.91-1.73]$ & 0.160 & $1.83[1.04-3.25]$ & 0.038 \\
\hline
\end{tabular}

\section{Petting/fondling}

Frequency of alcohol

consumption $^{1}$

Never/rarely

Regularly

1.00

Frequently

$1.31[0.83-2.06] \quad 0.246$

1.00

Binge drinking $^{2}$

$$
\text { No }
$$
$1.57[1.00-2.48]$

0.051

$2.06[1.38-3.07]<0.001$

$2.46[1.60-3.79] \quad<0.001$

Yes

1.00

1.08 [0.81-1.45] 0.609

1.00

$1.28[0.91-1.81] \quad 0.159$

$\mathrm{OR}=$ odds ratio $\mathrm{CI}=$ confidence interval.

All figures are adjusted for age, partner status, ethnicity, wealth, limiting long-standing illness, smoking status, physical activity and depressive symptoms at baseline, and weighted for sampling probabilities and differential non-response.

${ }^{1} \mathrm{Never} /$ rarely $=$ never - once or twice a year; regularly $=$ once every couple of months twice a week; frequently $=3$ days a week - almost every day.

${ }^{2}$ Defined as drinking $\geq 4$ units for women and $\geq 5$ units for men on the heaviest drinking day in the past week. 